\title{
Phylogenetic Evidence for the Gain and Loss of a Sexually Selected Trait in Sailfin Mollies
}

\author{
Margaret B. Ptacek, Michael J. Childress, Jennifer A. Petersen, and Anne O. Tomasso
}

Department of Biological Sciences, Clemson University, 132 Long Hall, Clemson, SC 29634-0314, USA

Correspondence should be addressed to Margaret B. Ptacek, mptacek@clemson.edu

Received 26 January 2011; Accepted 26 February 2011

Academic Editors: D. Russo, P. Scaps, and L. Vicente

Copyright (๑) 2011 Margaret B. Ptacek et al. This is an open access article distributed under the Creative Commons Attribution License, which permits unrestricted use, distribution, and reproduction in any medium, provided the original work is properly cited.

A phylogenetic comparative approach was used to examine the evolution of the enlarged "sailfin," characteristic of the monophyletic lineage of sailfin mollies (Poecilia: Mollienesia), but absent in one of its species, P. latipunctata. Ancestral character state reconstructions demonstrated that the ancestral sailfin molly possessed the enlarged sailfin, and, thus, males of $P$. latipunctata have secondarily lost this trait. The strength of female mating preference was measured in $P$. latipunctata for two known targets of sexual selection, large male size, and sailfin male phenotype. Females of $P$. latipunctata preferred conspecific males of larger body size to those of smaller body size, but showed no preference for sailfin males of a related species, $P$. velifera, when compared with males of the shortfin species, $P$. mexicana. Taken together, these results suggest that the targets of sexual selection may have shifted in this species and that reduction in female preference for sailfin males may have played a role in the loss of this ornament.

\section{Introduction}

Studies in sexual selection have primarily focused on the role of female mating preferences in the origin, elaboration, and maintenance of male traits used as mating signals [1]. Studies using phylogenetic comparisons, however, are beginning to show that the loss of sexually selected male traits may be nearly as common as their gain, at least for some groups (reviewed in [2]). Such examples seem paradoxical in the light of numerous studies that have demonstrated strong female mating preferences for exaggerated male signaling traits $[1,3,4]$. Indeed, the loss of exaggerated male traits implies that other forces of evolution are able to overcome the power of sexual selection or that sexual selection may become weaker over time or even reverse in direction [2]. Thus, the reduction, loss or reversal of female mating preferences [5-10] suggests that female choice may play a role in the loss of male signaling traits, as well as their gain.

Phylogenetic comparative studies of groups in which some species are sexually dimorphic for male display ornaments and others are not provide an opportunity to reconstruct the ancestral states of these male traits and determine the pattern of gains and losses leading to extant species [1113]. Combining these analyses with an examination of female mating preferences in species that have lost male display ornaments provides a test of the hypothesis that reduction or shifts in female mating preferences result in weaker selection on exaggerated signaling traits, hence, allowing other evolutionary forces to promote their loss.

Molly fishes (Poeciliidae: Poecilia: Mollienesia) are a good group in which to examine the evolution of male display ornaments and female preferences for those ornaments for several reasons. First, mollies are divided into two monophyletic lineages, sailfins, and shortfins (Figure 1), which vary in their expression of courtship behaviors and degree of exaggeration of display ornaments $[14,15]$. Shortfin species, such as $P$. mexicana, lack sexual dimorphism in dorsal fin morphology, and males of most shortfin species do not perform courtship displays. In contrast, with the exception of $P$. latipunctata, males of sailfin species have greatly enlarged dorsal fins, hence the name "sailfin." Males of all four sailfin molly species perform a courtship display where a male orients nearby a female, spreads the dorsal fin rays, and bends his body into a C- or sigmoid-shape while quivering the 
body $[14,16-20]$. The exaggerated "sailfin" ornament is thought to enhance the visibility of the display $[16,21$, 22] and increases a male's overall size when courting a female $[23,24]$. Receptive females respond to this display by remaining stationary and accepting copulations [14,25]. Thus reproductive success in sailfin mollies appears to be strongly influenced by female mate choice and sexual selection $[4,14,25]$.

Second, sensory exploitation [26-28] may have played an important role in the evolution of the enlarged dorsal fin that enhances the courtship display in most sailfin species [23-25]. For example, females of the sailfin species $P$. latipinna prefer larger males [29-31] and, when males are of the same length, males with larger dorsal fins [23]. Female preference for larger dorsal fins, however, appears to be based on preference for larger apparent male size, with females preferring males with larger overall lateral projection areas (LPA: sum of body and dorsal and caudal fin areas), regardless of whether increased LPA is due to larger body size or larger dorsal fin size [23]. Thus, a larger dorsal fin may exploit the preexisting sensory bias in females for "larger" males.

In addition to female preferences for larger sailfins in P. latipinna, other sailfin species (P. velifera and P.petenensis; [24]) and even shortfin molly species [25] also show such preferences for a generalized "sailfin male phenotype." Ptacek [25] showed that females of two shortfin species, P. mexicana and $P$. orri, preferred sailfin males (P. latipinna) to males of heterospecific shortfin species. They showed no preference in choice tests comparing conspecific males and sailfin males but did prefer conspecific males to males of a different shortfin species. Thus, preference for sailfin males appears to be ancestral in mollies and evolved prior to the evolution of the enlarged dorsal fin that is found in three of four members of the sailfin molly lineage $[15,25]$.

A final reason for interest in mollies as a model for studies of the gain and loss of sexually selected traits is that within the sailfin molly lineage, one species, P. latipunctata, lacks the enlarged dorsal fin, which is characteristic of males of all other species of sailfin mollies. Despite its lack of a sailfin, $P$. latipunctata is a well-supported member of the monophyletic sailfin molly lineage based upon both nuclear and mitochondrial DNA phylogenies $[15,34]$. In addition, behavioral studies have demonstrated that males of $P$. latipunctata perform courtship displays that are indistinguishable in elements and function to that of courtship displays used by males of all other sailfin molly species to elicit female cooperation in mating $[19,20]$.

In this paper, we present the results of a phylogenetic comparative study designed to (1) reconstruct the ancestral character state of the sailfin in the ancestral sailfin molly, (2) determine the pattern of gains and losses of the sailfin in extant species since divergence from shortfin ancestors, and (3) determine the strength of female mating preferences in P. latipunctata for large male size and the sailfin male phenotype. Our primary aim was to determine if males of P. latipunctata have secondarily lost the sailfin and if changes in the strength of female mating preferences for sailfin males could have played a role in this loss.

\section{Materials and Methods}

2.1. Phylogenies and Ancestral State Reconstruction. The phylogenies used for ancestral character state reconstruction (Figure 2) were based upon the mitochondrial DNA (mtDNA) alignment of Ptacek and Breden [15]. We chose to use this data set rather than the nuclear protooncogene sequence alignment of Schartl et al. [34] because the mtDNA alignment contains all four sailfin species while the nuclear data set is missing $P$. petenensis [34]. Eleven species of Mollienesia plus the South American species P. caucana were included in the phylogenetic analyses; the South American molly, $P$. vivipara, and the guppy, $P$. reticulata, were used as outgroups.

Two regions were sequenced and combined in the alignment of the 14 taxa (see [15] for detailed methods) and used in the phylogenetic analyses: the entire NADH dehydrogenase subunit 2 (ND2) mitochondrial gene (1047 bp) and approximately $550 \mathrm{bp}$ of the mitochondrial control region (D-loop). The resulting trees were based on maximum parsimony (MP) and maximum likelihood (ML) analyses as implemented in PAUP* (Version 4.0b10, [35]). The maximum-likelihood model used was the best-fit model found by MODELTEST [36], which was a general timereversible model with estimates of invariant sites and a $\gamma$-distribution estimated using PAUP*. The topologies from these two methods differed only with respect to the placement of $P$. latipinna within the sailfin molly lineage (Figure 2).

We chose to use a maximum likelihood approach [37] as implemented in the computer program DISCRETE $[32,38]$ to reconstruct the ancestral states of the sailfin (present or absent) at each internal node for both the MP and ML trees. Likelihood reconstructions used a continuous time Markov model of evolutionary change for reconstructing ancestral states of discrete characters, assuming that (1) probability of change in a character depends only on the character's present state and not any previous states, (2) changes along branches are independent of changes elsewhere in the tree, and (3) rates of change are constant throughout the tree $[33,38]$. An advantage of likelihood-based reconstructions over unordered or simple parsimony [39-41] is the ability to incorporate information on branch lengths (and hence tempo of evolution) and, thus, to differentiate between possible ancestral states at a given node [42]. Thus, using a likelihood approach, we can assess the probability that a character is reconstructed given a certain state, as well as the probability for reconstructing the character in alternative states [43]. The three sailfin species where males possess the enlarged dorsal sailfin were coded as "sailfin present" and P. latipunctata was coded as "sailfin absent" in the DISCRETE analyses. Branch lengths were either the number of nucleotide substitutions along each branch for the MP tree or the average number of substitutions per site along each branch for the ML tree. For each node in the two phylogenies, we calculated the log-likelihood of presence and absence of the enlarged sailfin. We then used a likelihood ratio (LR) test to compare the goodness of fit of a model with the ancestral state being absence of the sailfin $\left(H_{0}\right)$ to 


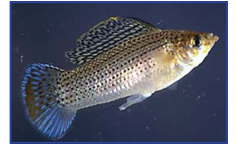

(a)

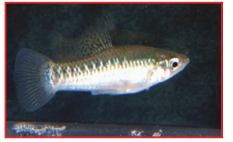

(b)

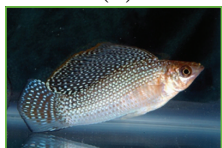

(c)

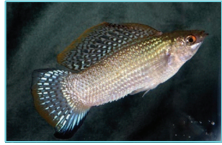

(d)

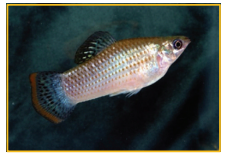

(e)

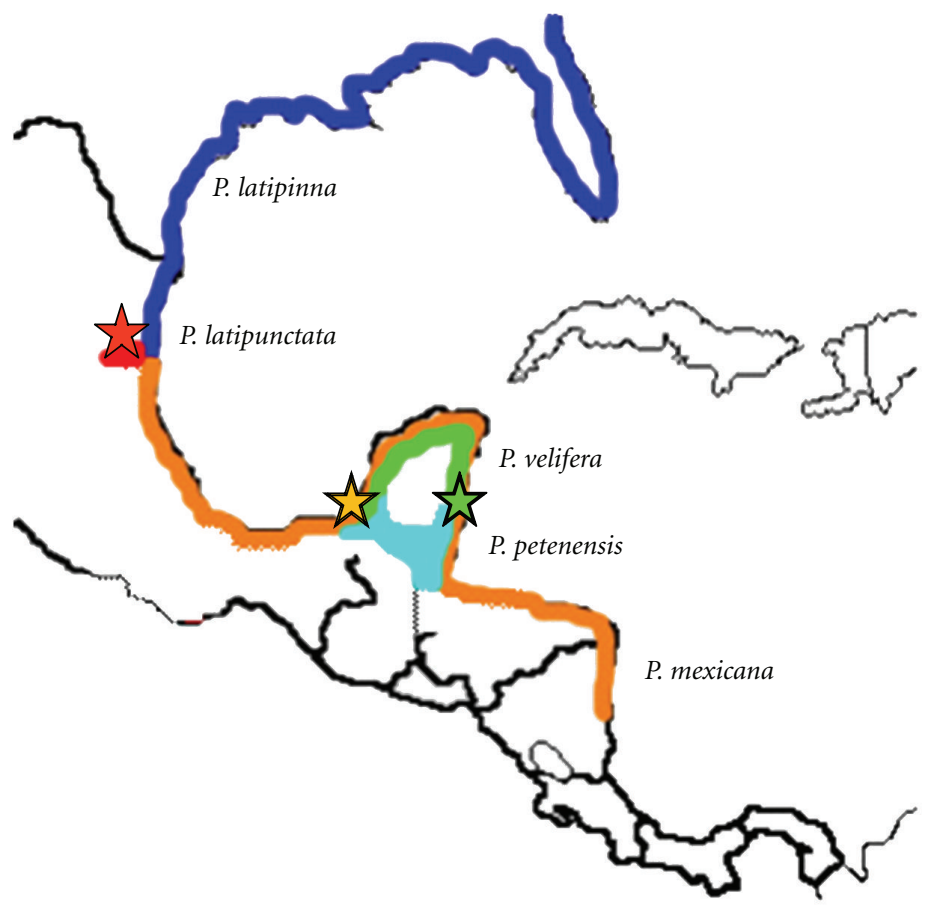

FIgure 1: Photographs and map of the geographic distribution of four sailfin mollies and one shortfin molly. The sailfin mollies are P. latipinna ((a) dark blue), P. latipunctata ((b) red), P. velifera ((c) green), and P. petenensis ((d) light blue), and the shortfin molly is P. mexicana ((e) orange). The collecting locations for the three species used in this study are indicated by the filled stars. Photos were taken by David Lewis.

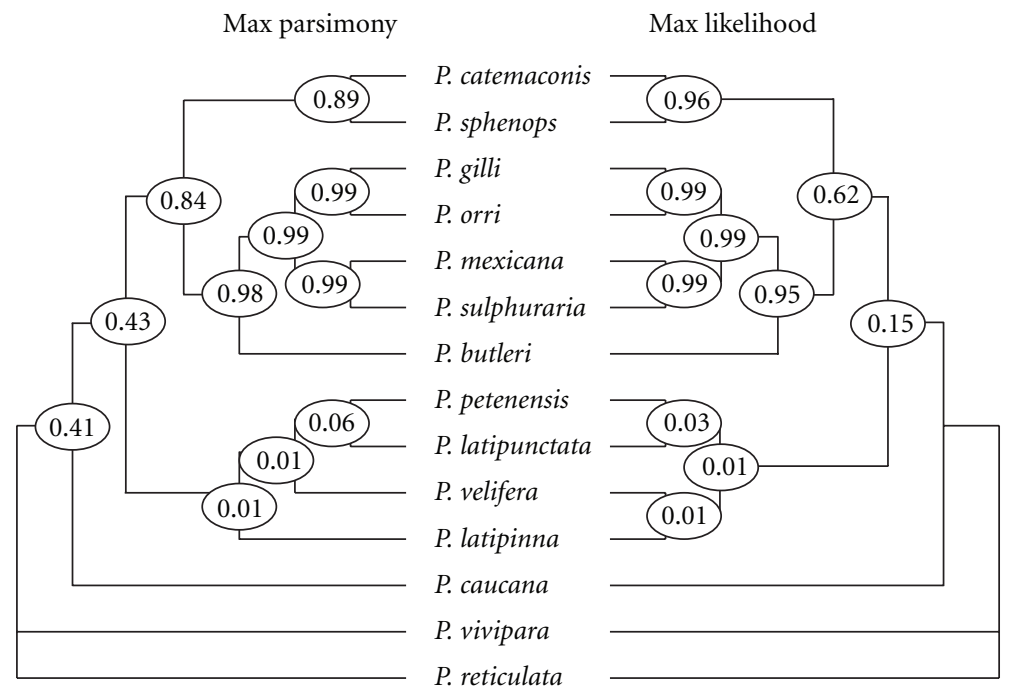

Figure 2: Maximum likelihood ancestral state reconstructions (MULTISTATE; $[32,33]$ ) of the presence of the "sailfin" in 12 species of mollies using inferred branch lengths from the shortest length MP and single best ML trees from Ptacek and Breden [15]. Numbers in circles for each node are $P$ values based on likelihood ratio tests of significance of "sailfin present" as the ancestral state.

that of a model of presence of the sailfin $\left(H_{1}\right)$ with the LR statistic defined as $\mathrm{LR}=-2 \log _{e}\left[H_{0} / H_{1}\right]$. We used a Bayesian context to interpret our likelihoods $[37,44]$. The alternative states at each node were regarded as equiprobable a priori; thus the posterior probability of a state is proportional to its likelihood. For example, a likelihood ratio of 9 would correspond to a posterior probability of 0.9 in favor of the best ML estimate.

2.2. Collection and Maintenance of Experimental Fish. The Tamesí molly, P. latipunctata, is a freshwater molly restricted to a single drainage (Río Tamesí) in the Mexican state of 
Tamaulipas (Figure 1). Fishes were collected in March of 2002 and 2003 from a natural spring near Ciudad Mante, Tamaulipas, Mexico and shipped back to laboratory facilities at Clemson University. We collected no more than 100 adult males and females from this population in the two sampling years, only seining in a small portion of the spring ( $<10 \%$ of total area), thus, minimizing disturbance and impact of our collecting activities on this natural population. Individuals of the sailfin species $P$. velifera were collected from a single population near Tulúm, Quintana Roo, Mexico in 1999, and individuals of the shortfin species $P$. mexicana were collected from a single population near Chompotón, Campeche, Mexico in 2001 and 2002 (Figure 1).

In the laboratory we maintained the fish in large Rubbermaid stock tanks (600 l) in calcium chloride-enriched freshwater at a $\mathrm{pH}$ of 7.0-7.4 for P. latipunctata and brackish water (6 ppt Instant Ocean) at a $\mathrm{pH}$ of 8.0 for P. velifera and $P$. mexicana, all at $25^{\circ} \mathrm{C}$. Lights were provided by Sylvania Gro-lux fluorescent bulbs (20 watt, full spectrum $350 \mathrm{~nm}-$ $750 \mathrm{~nm}$, with spectral peaks at 400, 440, and $540 \mathrm{~nm}$ ) and kept at a controlled 14:10 h light:dark cycle. Fish were fed once daily with commercial flake food (Ocean Star International Freshwater Flake $(60 \%)$ with Brine Shrimp Flake $(38 \%)$ and Spirulina Flake (2\%) mixture), dried algae wafers, and frozen brine shrimp (Artemia sp.). Care and housing conditions followed protocols approved by the Clemson University's Animal Research Committee (Protocol no. 20044). Test females of $P$. latipunctata and object males of $P$. latipunctata, $P$. velifera, and P. mexicana were subsequently transferred to 20-litre aquaria at least two weeks prior to experimental female choice trials, where they were kept under similar water, food, and lighting conditions as those used for stock tanks.

2.3. Object Male Size Estimates. Males from each population of the three species ( $P$. latipunctata, $n=29 ; P$. mexicana, $n=7$; . velifera, $n=8$ ) used as objects in dichotomous female choice trials were anesthetized (0.50\% MS-222, Sigma, Inc.), placed on a dissection mat (left side up) with the dorsal and caudal fins fully spread, and photographed with a digital camera (Sony DSC-F707) at $2560 \times 1920$ resolution. Standard length (SL) and area measurements were estimated from the digital photographs using image analysis software (NIH Image and TpsDig (Version 1.37)) for males $25-50 \mathrm{~mm}$ SL (size range of male SL of object males used in female choice trials). Males of appropriate SL, LPA ratio, and species differences (Figure 3 ) were then paired and used as object males in female choice tests resulting in slightly different numbers of male combinations in each treatment ( $P$. latipunctata versus $P$. mexicana ( $n$ of combinations $=6$ ) and $P$. velifera versus $P$. mexicana ( $n$ of combinations $=10)$ ).

2.4. Female P. latipunctata Choice Tests. In the first experiment, we tested 16 receptive females (postpartum $24-48 \mathrm{~h}$; $[25,29])$ each with a single treatment: a large male of $P$. latipunctata versus a small male of P. latipunctata. The difference in size between the two object males ranged from 7 to $10 \mathrm{~mm} \mathrm{SL}$ ( $n$ of combinations of object males $=10$, mean difference in male size $=9 \mathrm{~mm}$, and mean LPA ratio $($ large $:$ small $)=1.82$ ). To control for side biases by females, the position of the large male (right versus left side of the choice tank) was alternated between females tested.

We conducted female choice tests in a 75-litre aquarium ( 122 by 32 by $52 \mathrm{~cm}$ ) with the two sections at the ends of the tank (each 24 by 32 by $52 \mathrm{~cm}$ ) partitioned with panels of clear plexiglass with slits at the top of each that allowed water flow. These two end sections constituted the two male compartments. The central portion of the tank allowed a female to move freely from one partitioned side to the other, observing males through the clear plexiglass dividers. We used calcium chloride-enriched freshwater in the choice tank in order to optimize conditions for the females of P. latipunctata, whose behavior was being measured. We followed testing protocols similar to those used previously [24, 25, 29]; female preference during a trial was measured as the amount of time during a 10-minute observation period that a female spent within $10 \mathrm{~cm}$ of the partition (preference zone) for each male compartment.

In the second experiment, we used the same dichotomous choice tank and tested 15 receptive females (postpartum 24-48 h; different females from those used in the first experiment), each with two different male treatments: $P$. latipunctata versus $P$. mexicana ( $n$ of combinations $=6$, mean object male SL $=44 \mathrm{~mm}$, and range $=42-46 \mathrm{~mm}$ ) and $P$. velifera versus $P$. mexicana ( $n$ of combinations $=10$, mean object male $\mathrm{SL}=44 \mathrm{~mm}$, and range $=35-50 \mathrm{~mm}$ ). Males were matched for size within $2 \mathrm{~mm} \mathrm{SL}$, but differed in LPA due to species-specific differences in dorsal fin area (Figure 3). The presentation order of male treatment combinations was alternated between test females (eight of the females first saw the $P$. latipunctata versus $P$. mexicana male treatment combination followed by the $P$. velifera versus $P$. mexicana male treatment combination; the order was reversed for the other seven females tested) as was the side of the tank in which a particular species of male was presented (e.g., eight of the females saw the $P$. latipunctata male on the right side of the choice tank, and the other seven females saw the $P$. latipunctata male on the left side). The amount of time that a female spent in the preference zone (within $10 \mathrm{~cm}$ of the plexiglass divider) of each male was recorded during the 10-minute observation period. Strength of preference was measured as the time that the female spent with the conspecific male minus the time she spent with the male of $P$. mexicana or the time a female spent with the sailfin male of $P$. velifera minus the time she spent with the male of $P$. mexicana.

We used a $t$-test in the first female choice experiment to compare the average time spent with the larger male to the average time spent with the smaller male. We used a paired $t$-test in the second female choice experiment to compare the strength of preference for the sailfin male (difference in time spent with each male) between the two male treatment combinations. We also used $t$-tests to examine nuisance variables including left versus right side biases in both experiments and order of combination presentation effects in the second experiment. 


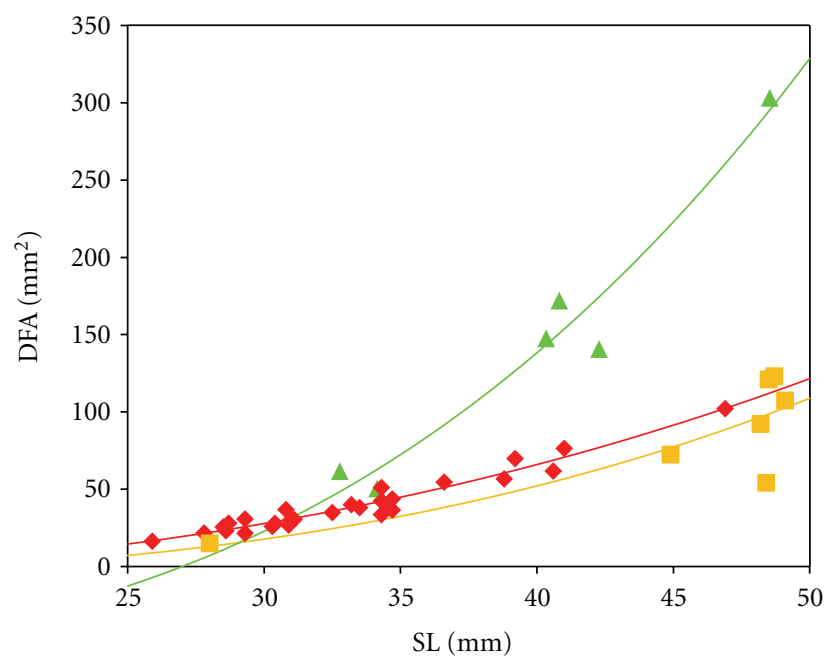

(a)

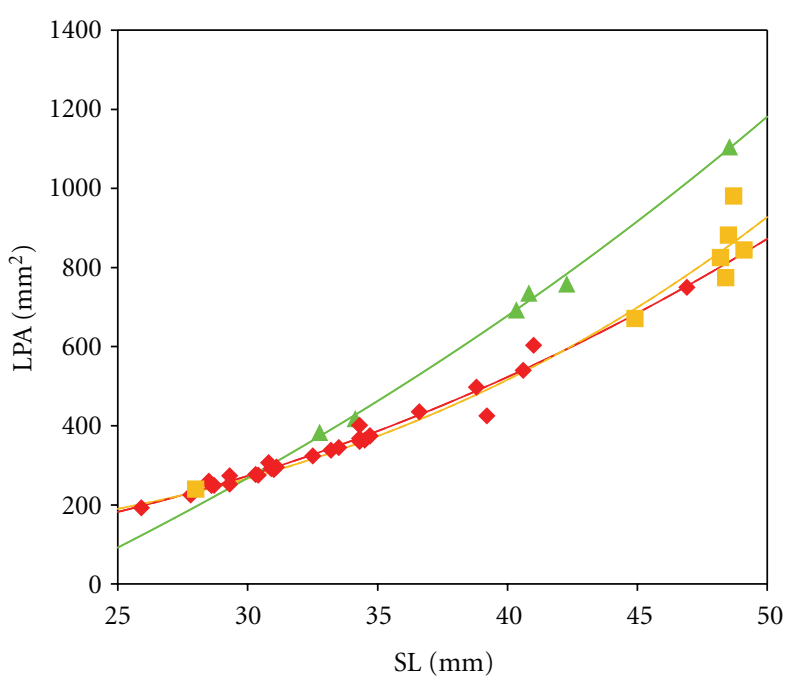

(b)

FIGURE 3: Relationships between SL (standard length in $\mathrm{mm})$ and (a) dorsal fin area $\left(\mathrm{mm}^{2}\right)$ and (b) lateral projection area $\left(\mathrm{mm}{ }^{2}\right)(\mathrm{LPA}=$ the sum of dorsal fin area (DFA) + caudal fin area (CFA) + body area (BA)) as estimated by a best-fit least-squares power function of $($ area $)=a$ $+b(\mathrm{SL})^{c}$ using curve fitting software (Table Curve 2D). P. velifera is shown as the green line with triangles $(\mathrm{DFA}-a=-8.53, b=0.00735$, and $c=2.5$; CFA $-a=-30.6, b=0.507$, and $c=1.5$; BA- $a=34.1, b=0.0321$, and $c=2.5)$. P. latipunctata is shown as the red line with diamonds (DFA $-a=-61.5, b=0.00312$, and $c=3.0$; CFA $-a=-480, b=98.0$, and $c=0.5$; BA- $a=-203, b=2.38$, and $c=1.5$ ). $P$. mexicana is shown as the orange line with squares (DFA $-a=-7.53, b=0.000929$, and $c=3.0 ; \mathrm{CFA}-a=-2.99, b=0.00184$, and $c=3.0 ; \mathrm{BA}-a=95.6, b=0.00397$, and $c=3.0)$.

\section{Results}

3.1. Ancestral Character State Reconstruction. Based upon ancestral state reconstructions using inferred branch lengths (those estimated from MP or ML phylogenetic analyses), the ancestral sailfin molly unequivocally possessed an enlarged sailfin (Figure 2). Thus males of P. latipunctata have secondarily lost the sailfin, and this result is strongly supported by both the MP and ML topologies. Strong statistical support (likelihood ratio probability values) for presence of the sailfin was inferred for all nodes within the sailfin molly clade, and likelihood reconstructions based on inferred branch lengths under parsimony (MP topology) were nearly identical to those based on inferred branch lengths under maximum likelihood (ML topology). Sailfin presence or absence is equivocal in the ancestor of Mollienesia; however, species outside of, but closely related to, Mollienesia are also shortfins [45].

3.2. Female Choice Tests. Females of P. latipunctata showed a strong preference for larger males ( $t$-test, d.f. $=14, t=4.10$, and $P=.001$ ) and spent nearly three times more time with the larger male than with the smaller male (Figure 4 ). This result was not dependent upon which side of the choice tank the larger male was placed (time with large male left versus right: $t$-test, d.f. $=14, t=-0.967$, and $P=.350)$. Thus, these results demonstrate that females of $P$. latipunctata retain the ancestral bias favoring large males that is characteristic of many species of poeciliids [24, 29, 46, 47].

When females were tested twice, each with two different male species combinations, there was no significant effect of treatment presentation order on the strength of female mating preferences ( $P$. latipunctata versus $P$. mexicana first: $t$-test, d.f. $=13, t=1.765$, and $P=.101 ; P$. velifera versus $P$. mexicana first: $t$-test, d. f. $=13, t=-0.353$, and $P=$ .730). Neither was there any evidence of side biases in the $P$. latipunctata versus $P$. mexicana male treatment combination (time with $P$. latipunctata male left versus right: $t$-test, d.f. $=13, t=-0.666$, and $P=.517$; time with $P$. mexicana male left versus right: $t$-test, d.f. $=13, t=-1.288$, and $P=.220)$ nor in the $P$. velifera versus $P$. mexicana male treatment combination (time with $P$. velifera male left versus right: $t$-test, d.f. $=13, t=-0.059$, and $P=.954$; time with $P$. mexicana male left versus right: $t$-test, d.f. $=13, t=0.795$, and $P=.441)$.

Females of $P$. latipunctata clearly preferred the conspecific male and spent nearly three times more time with the male of $P$. latipunctata than with the male of $P$. mexicana (Figure 5). Females did not, however, prefer the sailfin male, $P$. velifera, to the shortfin male, $P$. mexicana (Figure 5). This lack of preference for the sailfin male occurred despite the apparent larger size of males of $P$. velifera due to their increased dorsal fin area as compared to that of males of $P$. mexicana (estimated mean LPA ratio across range of object males used $=1.32$; Figure 3 ). The strength of female preference was significantly greater (paired $t$-test, d.f. $=14$, $t=2.325$, and $P=.036$ ) for the male combination of $P$. latipunctata versus $P$. mexicana (mean difference $=$ $189.73 \mathrm{~s} \pm 47.68)$ than the male combination of $P$. velifera versus $P$. mexicana (mean difference $=-35.2 \mathrm{~s} \pm 74.48$ ). Thus, females of $P$. latipunctata appear to lack the generalized preference for sailfin males, which is characteristic of other sailfin molly species [24] and some shortfin species of mollies [25]. 


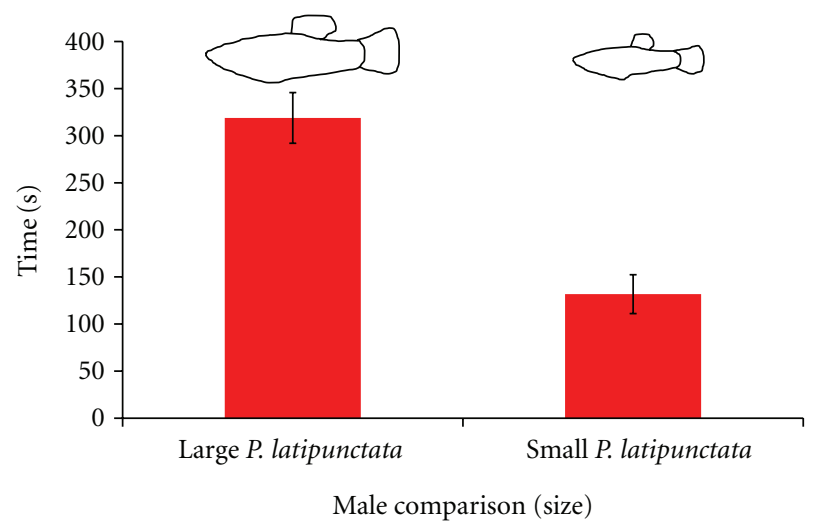

Figure 4: Results of dichotomous choice tests for females of $P$. latipunctata $(n=16)$ that compared body size differences between a large male of $P$. latipunctata and a small male of $P$. latipunctata. The average $( \pm$ s.e.m.) time spent during a 10 -minute observation period with each male is plotted.

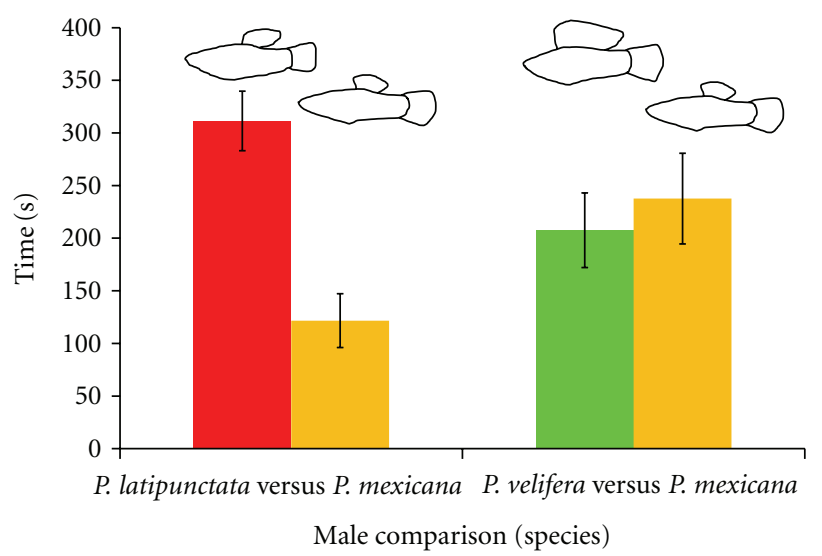

FIgURE 5: Results of dichotomous choice tests for females of $P$. latipunctata $(n=15)$ that compared species differences between males matched for body length in two different male treatment combinations ( $P$ latipunctata versus $P$. mexicana and $P$. velifera versus $P$. mexicana). The average $( \pm$ s.e.m.) time spent during a 10 minute observation period with each male from the two different male treatment combinations is plotted.

\section{Discussion}

The loss of the sailfin in P. latipunctata adds to a growing number of examples of the loss of sexually selected male traits [2]. The more interesting question of why did males of $P$. latipunctata lose the sailfin remains to be answered. This is a difficult but especially intriguing question to answer, in light of the observation that sensory exploitation appears to predispose female mollies to prefer males with larger sailfins, hence enhancing their apparent body size [23-25]. Wiens [2] suggests that there are at least three potential types of factors that may explain why a sexually selected male trait could be lost: environmental, social, and random.

Environmental features are known to influence the evolution of male signaling traits and these include the effects of natural selection through predation risk, signal transmission, and energetic costs of signal ornaments in terms of maintenance and their influence on performance [48, 49]. Poecilia latipunctata is a freshwater species endemic to northeastern Mexico and has a very narrow geographic distribution, being restricted to a single river (Río Tamesí) in the Mexican state of Tamaulipas [50,51]. Today this species is found primarily in smaller tributaries and headwater springs, being extirpated from downstream larger river habitats, as a result of pollution and other anthropogenic effects (S. Contreras-Balderas, pers. comm.). The primary predators of $P$. latipunctata include piscivorous cichlids, aerial bird predators such as kingfishers, and wading birds such as herons and egrets (M. Ptacek, pers. obs.).

Compared to other sailfin species, male size at maturity is extremely narrow in P. latipunctata [20,52]. For example, males of $P$. latipunctata from the natural population used in this study ranged in SL from 23 to $46 \mathrm{~mm}$. In comparison, males of $P$. velifera range in SL at maturity from 19 to $84 \mathrm{~mm}$ and males of $P$. petenensis in SL from 33 to $110 \mathrm{~mm}$ $[53,54]$. Male size at maturity in mollies is thought to be controlled by a similar Y-linked genetic architecture as that found in Xiphophorus ( $P$ locus system described by $[55,56]$ ) producing a normal distribution of male sizes in natural populations, with sons maturing at nearly identical sizes to those of their fathers [57]. Thus, for males of P. latipunctata, the distribution of $P$ alleles for male size at maturity has been dramatically truncated.

There are several potential natural selection explanations that would favor small male size at maturity in mollies. The genetic control of the $P$ locus on male maturation exerts its influence on the time to maturity; smaller males mature sooner than large males [55-57]. Hence there is a strong natural selection advantage to small male size through earlier maturation and continuous reproductive activity $[57,58]$. In addition, studies in P. latipinna have also shown that wading birds selectively prey on large mollies, and thus smaller males have a predation risk advantage over large males [59]. Both of these natural selection advantages of small male size could potentially operate in natural populations of $P$. latipunctata and favor the loss of large-sized males.

Dorsal fin size in all sailfin molly species shows a strong positive allometric relationship with male SL $[23,52,57]$. However the strength of this allometry varies between species [52], leading to dramatic differences between species in sailfin size for a given male body length (Figure 3(a)). Thus, reduction in the frequency of $P$ alleles for large male size at maturation in P. latipunctata would lead also to a reduction in dorsal fin size in this species of sailfin molly.

Social factors leading to the loss of a sexually selected trait include the potential role of that trait in male-male competition and as a target of female choice [2]. Male-male competition is probably of lesser importance in this species, as males of $P$. latipunctata are not overtly aggressive to one another [20], which is also true for other sailfin species $[14,57]$. In marked contrast, males of shortfin species, such as $P$. mexicana, form male-male dominance hierarchies with the largest, dominant male becoming much darker in coloration and actively chasing and biting at subordinate 
males to prevent their access to receptive females $[60,61]$. Interestingly, certain males of $P$. latipunctata, usually larger males, take on darker body coloration similar to that of dominant shortfin males, but instead of showing increased levels of agonistic behaviors, they greatly elevate their courtship display rates in the presence of receptive females and competitor males [20]. Thus, competition for access to receptive females in this sailfin species may favor increased display rates rather than larger body or dorsal fin size, in a similar manner to that of other poeciliids $[14,62]$ including P. latipinna [63].

Prior studies of female mating preferences in other poeciliid species in which the male trait has been lost have yielded conflicting evidence with respect to the role of changes in female choice in promoting the loss of the male trait. For example, in swordtail fishes (Xiphophorus nigrensis and $X$. pygmaeus), in which the sexually selected male trait "vertical bars" has been lost, female preferences have been lost for the trait in one species (X. pygmaeus), yet the trait is still favored by females of another species (X. nigrensis; [6]). In a third species, $X$. cortezi, males are polymorphic for the presence of vertical bars and females exhibit a polymorphism in preference, some favoring males with bars and some favoring males without bars [64]. Finally, in X. continens, where males have lost both large body size and vertical bars, females have lost the preference for larger-sized males but retained a preference for vertical bars [8]. These studies do, however, suggest that loss of sexually selected male traits in poeciliid fishes is often accompanied by weakening of female preferences for these traits or a switch in female preference to an alternative male signal.

In addition to changes in the strength of female mating preferences for male display ornaments that have been lost, females may use other signal features in mate choice [65, 66] and these features may become more important in mating decisions by females of species where males have lost particular display ornaments. For example, females often express preferences for an emergent property of a male's signal such as larger size or greater conspicuousness $[3,23,28,48,67,68]$. When different trait values can be combined in different ways to create the impression of larger size or increased conspicuousness, different combinations of individual male trait values may be equally attractive to females $[66,69]$, leading to permissive female preferences [70].

Such a shift in the targets of female mating preferences to traits other than the enlarged sailfin may be at work in P. latipunctata. While females of this species preferred larger conspecific males to smaller ones, they did not show a generalized preference for the "sailfin male phenotype" as expressed by males of $P$. velifera when compared to males of the shortfin P. mexicana. If mating preferences in this species were based merely on favoring males with the largest LPA, then females should have preferred males of $P$. velifera to males of $P$. mexicana (Figure $3(\mathrm{~b})$ ) even though these sailfin males were heterospecifics. Female preference for heterospecific males has been shown for other poeciliids including one species of swordtail (X. pygmaeus; [71]), two species of sailfin mollies (P. velifera and P. petenensis; [24]), and two species of shortfin mollies (P. orri and P. mexicana; [25]) and is thought to be due to the expression of traits by males of these species that are the targets of preexisting female sensory biases. The lack of preference for the heterospecific sailfin males in our trials, however, may not have been because these males possessed large sailfins but, rather, because they lacked some preferred trait, such as dark body coloration or high courtship display rates, which is characteristic of conspecific males. Alternatively, males of $P$. velifera may have expressed species-specific traits in addition to their large sailfins that females of $P$. latipunctata find unattractive or do not recognize as necessary and sufficient for mate recognition [72]. Future studies are needed using conspecific males that vary in dorsal fin size in order to determine whether females of $P$. latipunctata have truly lost their preference for males with larger dorsal fins. Models such as those used by MacLaren et al. [23] and Kozak et al. [24] offer a promising avenue to explore such female preferences.

Lastly, genetic drift is often cited as a possible cause for the loss of male traits. Some support for this hypothesis comes from the observation that losses of conspicuous plumage coloration in birds occur frequently in small populations on islands [73]. Drift in small populations may be responsible for loss of the male trait directly, or indirectly, through genetic drift effects on the direction of female choice as well, possibly causing a loss or change in the female preference that favors the loss of the male trait $[10,74]$. Such a role for genetic drift in the loss of the sailfin and/or the weakening of preference for sailfin males by females of $P$. latipunctata is plausible. The position of $P$. latipunctata within the sailfin molly lineage as sister to the freshwater species $P$. petenensis from the Yucatán peninsula region of Mexico is strongly supported in both MP and ML trees (Figure 2; [15]). One potential biogeographic scenario for this strong sister relationship between two such geographically distant taxa is one of a historically continuous distribution of "freshwater" sailfin mollies when ocean levels of the Gulf of Mexico were higher [75]. Populations of $P$. latipunctata may have become isolated inland (and restricted to the Río Tamesí drainage) when ocean levels retreated. Such a bottleneck effect would explain why male body size at maturity is so narrow and dorsal fin ray number is nearly fixed at 11 dorsal fin rays for males from the spring population used in this study. An examination of neutral genetic variation in this population is needed to test the hypothesis of a bottleneck effect promoting the loss of the sailfin and/or female preference for the sailfin male phenotype.

Overall, our study provides yet another example of the loss of a male sexually selected trait. Potential explanations for this loss include a natural selection advantage to smaller males with smaller sailfins, a possible role of genetic drift in the loss of alleles for large male size and size-associated dorsal fin size, and the reduction in female mating preferences for "sailfin" males, as suggested by our mate choice trials. While we cannot distinguish which evolutionary force was most important in promoting the loss of the sailfin in $P$. latipunctata, our study does suggest that changes in the strength of female mating preferences may influence the loss, 
as well as the gain, of male sexually selected traits. Future studies should shed light upon the importance of shifts in the targets of female choice in this species and the role of such changes in female mating preferences in the gain and loss of sexually selected traits in sailfin species of mollies.

\section{Acknowledgments}

The authors thank the Mexican government for permission to collect mollies, Ewen Harrison and José Luis Ramirez for assistance with field collections, Michele Kittell for laboratory care of fishes, and Rick Blob, Becky Fuller, Carl Gerhardt, Shala Hankison, Mark Kirkpatrick, Molly Morris, Mohamed Noor, Joe Travis and the Travis Reading Group, and especially John Wiens for their constructive comments on earlier drafts of this paper. This work was supported by the National Science Foundation, Animal Behavior Program (IBN 0296173 to MBP), and the Howard Hughes Medical Institute Undergraduate Research Awards program (JAP).

\section{References}

[1] M. Andersson, Sexual Selection, Princeton University Press, Princeton, NJ, USA, 1994.

[2] J. J. Wiens, "Widespread loss of sexually selected traits: how the peacock lost its spots," Trends in Ecology and Evolution, vol. 16, no. 9, pp. 517-523, 2001.

[3] M. J. Ryan and A. Keddy-Hector, "Directional patterns of female mate choice and the role of sensory biases," American Naturalist, vol. 139, pp. S4-S35, 1992.

[4] M. B. Ptacek, "The role of mating preferences in shaping interspecific divergence in mating signals in vertebrates," Behavioural Processes, vol. 51, no. 1-3, pp. 111-134, 2000.

[5] G. P. Sætre, T. Moum, S. Bureš, M. Král, M. Adamjan, and J. Moreno, "A sexually selected character displacement in flycatchers reinforces premating isolation," Nature, vol. 387, no. 6633, pp. 589-592, 1997.

[6] M. R. Morris, "Further examination of female preference for vertical bars in swordtails: preference for 'no bars' in a species without bars," Journal of Fish Biology, vol. 53, pp. 56-63, 1998.

[7] S. C. Griffith, I. P. F. Owens, and T. Burke, "Female choice and annual reproductive success favour less-ornamented male house sparrows," Proceedings of the Royal Society B, vol. 266, no. 1421 , pp. 765-770, 1999.

[8] M. R. Morris, J. A. Moretz, K. Farley, and P. Nicoletto, "The role of sexual selection in the loss of sexually selected traits in the swordtail fish Xiphophorus continens," Animal Behaviour, vol. 69, no. 6, pp. 1415-1424, 2005.

[9] N. W. Bailey, J. R. McNabb, and M. Zuk, "Preexisting behavior facilitated the loss of a sexual signal in the field cricket Teleogryllus oceanicus," Behavioral Ecology, vol. 19, no. 1, pp. 202-207, 2008.

[10] R. M. Tinghitella and M. Zuk, "Asymmetric mating preferences accommodated the rapid evolutionary loss of a sexual signal," Evolution, vol. 63, no. 8, pp. 2087-2098, 2009.

[11] K. J. Burns, "A phylogenetic perspective on the evolution of sexual dichromatism in tanagers (Thraupidae): the role of female versus male plumage," Evolution, vol. 52, no. 4, pp. 1219-1224, 1998.

[12] J. J. Wiens, "Phylogenetic evidence for multiple losses of a sexually selected character in phrynosomatid lizards," Proceedings of the Royal Society B, vol. 266, no. 1428, pp. 1529-1535, 1999.
[13] R. T. Kimball, E. L. Braun, D. J. Ligon, V. Lucchini, and E. Randi, "A molecular phylogeny of the peacock-pheasants (Galliformes: Polyplectron spp.) indicates loss and reduction of ornamental traits and display behaviours," Biological Journal of the Linnean Society, vol. 73, no. 2, pp. 187-198, 2001.

[14] J. A. Farr, "Sexual selection and secondary sexual differentiation in poeciliids: determinants of male mating success and evolution of female choice," in Ecology and Evolution of Livebearing Fishes (Poeciliidae), G. K. Meffe and F. F. Snelson Jr., Eds., pp. 91-123, Prentice Hall, Englewood Cliffs, NJ, USA, 1989.

[15] M. B. Ptacek and F. Breden, "Phylogenetic relationships among the mollies (Poeciliidae: Poecilia: Mollienesia group) based on mitochondrial DNA sequences," Journal of Fish Biology, vol. 53, pp. 64-81, 1998.

[16] J. Parzefall, "On comparative ethology of various Mollienesia species inclusive of a cave form of M. sphenops," Behaviour, vol. 33, no. 1, pp. 1-38, 1969.

[17] J. Parzefall, "Sexual and aggressive behaviour in species hybrids of Poecilia mexicana and P. velifera: (Pices, Poeciliidae)," Ethology, vol. 82, pp. 101-115, 1989.

[18] J. A. Farr, J. Travis, and J. C. Trexler, "Behavioural allometry and interdemic variation in sexual behaviour of the sailfin molly, Poecilia latipinna (Pisces: Poeciliidae)," Animal Behaviour, vol. 34, no. 2, pp. 497-509, 1986.

[19] A. Niemeitz, R. Kreutzfeldt, M. Schartl, J. Parzefall, and I. Schlupp, "Male mating behaviour of a molly, Poecilia latipunctata: a third host for the sperm-dependent Amazon molly, Poecilia formosa," Acta Ethologica, vol. 5, no. 1, pp. 4549, 2002.

[20] M. B. Ptacek, M. J. Childress, and M. M. Kittell, "Characterizing the mating behaviours of the Tamesí molly, Poecilia latipunctata, a sailfin with shortfin morphology," Animal Behaviour, vol. 70, no. 6, pp. 1339-1348, 2005.

[21] C. T. Regan, "A revision of the cyprinodont fishes of the subfamily Poeciliinae," Proceedings of the Zoological Society of London, vol. 11, pp. 977-1018, 1913.

[22] C. L. Hubbs, "Species and hybrids of Mollienesia," Aquarium, vol. 1, no. 1, pp. 263-268, 277, 1933.

[23] R. D. MacLaren, W. J. Rowland, and N. Morgan, "Female preferences for sailfin and body size in the sailfin molly, Poecilia latipinna," Ethology, vol. 110, no. 5, pp. 363-379, 2004.

[24] H. L. Kozak, L. A. Cirino, and M. B. Ptacek, "Female mating preferences for male morphological traits used in species and mate recognition in the Mexican sailfin mollies, Poecilia velifera and Poecilia petenensis," Behavioral Ecology, vol. 19, no. 3, pp. 463-474, 2008.

[25] M. B. Ptacek, "Interspecific mate choice in sailfin and shortfin species of mollies," Animal Behaviour, vol. 56, no. 5, pp. 11451154, 1998.

[26] M. J. Ryan, "Sexual selection, receiver biases, and the evolution of sex differences," Science, vol. 281, no. 5385, pp. 1999-2003, 1998.

[27] J. A. Endler and A. L. Basolo, "Sensory ecology, receiver biases and sexual selection," Trends in Ecology and Evolution, vol. 13, no. 10, pp. 415-420, 1998.

[28] J. W. Boughman, "How sensory drive can promote speciation," Trends in Ecology and Evolution, vol. 17, no. 12, pp. 571-577, 2002.

[29] M. B. Ptacek and J. Travis, "Mate choice in the sailfin molly, Poecilia latipinna," Evolution, vol. 51, no. 4, pp. 1217-1231, 1997. 
[30] C. Gabor, "Association patterns of sailfin mollies (Poecilia latipinna): alternative hypotheses," Behavioral Ecology and Sociobiology, vol. 46, no. 5, pp. 333-340, 1999.

[31] C. R. Gabor and R. Page, "Female preference for large males in sailfin mollies, Poecilia latipinna: the importance of predation pressure and reproductive status," Acta Ethologica, vol. 6, no. 1, pp. 7-12, 2003.

[32] M. Pagel, "Detecting correlated evolution on phylogenies: a general method for the comparative analysis of discrete characters," Proceedings of the Royal Society B, vol. 255, no. 1342, pp. 37-45, 1994.

[33] M. Pagel, "The maximum likelihood approach to reconstructing ancestral character states of discrete characters on phylogenies," Systematic Biology, vol. 48, no. 3, pp. 612-622, 1999.

[34] M. Schartl, B. Wilde, I. Schlupp, and J. Parzefall, "Evolutionary origin of a parthenoform, the Amazon molly Poecilia formosa, on the basis of a molecular genealogy," Evolution, vol. 49, pp. 827-835, 1995.

[35] D. L. Swofford, PAUP*. Phylogenetic Analysis Using Parsimony (* and Other Methods), Beta Version 4.0b10, Sinauer, Sunderland, Mass, USA, 2002.

[36] D. Posada and K. A. Crandall, "MODELTEST: testing the model of DNA substitution," Bioinformatics, vol. 14, no. 9, pp. 817-818, 1998.

[37] D. Schluter, T. Price, A. Ø. Mooers, and D. Ludwig, "Likelihood of ancestor states in adaptive radiation," Evolution, vol. 51, no. 6, pp. 1699-1711, 1997.

[38] M. Pagel, "Inferring evolutionary processes from phylogenies," Zoologica Scripta, vol. 26, no. 4, pp. 331-348, 1997.

[39] W. M. Fitch, "Toward defining the course of evolution: minimum change for a specific tree topology," Systematic Zoology, vol. 20, pp. 406-416, 1971.

[40] D. L. Swofford and W. P. Maddison, "Parsimony, characterstate reconstructions, and evolutionary inferences," in Systematics, Historical Ecology, and North American Freshwater Fishes, R. C. Mayden, Ed., pp. 186-223, Standford University Press, Palo Alto, Calif, USA, 1992.

[41] D. R. Maddison, "Phylogenetic methods for inferring the evolutionary history and processes of change in discretely valued characters," Annual Review of Entomology, vol. 39, pp. 267-292, 1994.

[42] D. L. Swofford, G. J. Olsen, P. J. Waddell, and D. M. Hillis, "Phylogenetic inference," in Molecular Systematics, D. M. Hillis, C. Mortiz, and B. Mable, Eds., pp. 407-509, Sinauer, Sunderland, Mass, USA, 2nd edition, 1996.

[43] M. Nepokroeff, K. J. Sytsma, W. L. Wagner, and E. A. Zimmer, "Reconstructing ancestral patterns of colonization and dispersal in the Hawaiian understory tree genus Psychotria (Rubiaceae): a comparison of parsimony and likelihood approaches," Systematic Biology, vol. 52, no. 6, pp. 820-838, 2003.

[44] Z. Yang, S. Kumar, and M. Nei, "A new method of inference of ancestral nucleotide and amino acid sequences," Genetics, vol. 141, no. 4, pp. 1641-1650, 1995.

[45] F. Breden, M. B. Ptacek, M. Rashed, D. Taphorn, and C. A. Figueiredo, "Molecular phylogeny of the live-bearing fish genus Poecilia (Cyprinodontiformes: Poeciliidae)," Molecular Phylogenetics and Evolution, vol. 12, no. 2, pp. 95-104, 1999.

[46] R. J. Bischoff, J. L. Gould, and D. I. Rubenstein, "Tail size and female choice in the guppy (Poecilia reticulata)," Behavioral Ecology and Sociobiology, vol. 17, no. 3, pp. 253-255, 1985.
[47] M. D. Crapon de Caprona and M. J. Ryan, "Conspecific mate recognition in swordtails, Xiphophorus nigrensis and $X$. pygmaeus (Poeciliidae): olfactory and visual cues," Animal Behaviour, vol. 39, no. 2, pp. 290-296, 1990.

[48] J. A. Endler, "Signals, signal conditions, and the direction of evolution," American Naturalist, vol. 139, supplement, pp. S125-S153, 1992.

[49] M. Zuk and R. M. Tinghitella, "Rapid evolution and sexual signals," in Sociobiology of Communication: An Interdisciplinary Perspective, P. d'Ettorre and D. P. Hughes, Eds., pp. 139-155, Oxford University Press, New York, NY, USA, 2008.

[50] R. Darnell, "Fishes of the Rio Tamesi and related coastal lagoons in east-central Mexico," Publications of the Institute of Marine Sciences, vol. 8, pp. 299-365, 1962.

[51] R. R. Miller, "Checklist and key to the mollies of Mexico (Pisces: Poeciliidae: Poecilia, subgenus Mollienesia)," Copeia, vol. 1983, pp. 817-822, 1983.

[52] S. J. Hankison and M. B. Ptacek, "Within and between species variation in male mating behaviors in the Mexican sailfin mollies Poecilia velifera and P. petenensis," Ethology, vol. 113, no. 8, pp. 802-812, 2007.

[53] J. J. Schmitter-Soto, Cátalogo de los Peces Continentals de Quintana Roo, ECOSUR: San Cristobal de Las Casas, Quintana Roo, Mexico, 1998.

[54] S. J. Hankison, M. J. Childress, J. J. Schmitter-Soto, and M. B. Ptacek, "Morphological divergence within and between the Mexican sailfin mollies, Poecilia velifera and Poecilia petenensis," Journal of Fish Biology, vol. 68, no. 5, pp. 16101630, 2006.

[55] K. D. Kallman, "Genetic control of size at maturity in Xiphophorus," in Ecology and Evolution of Livebearing Fishes (Poeciliidae), G. K. Meffe and F. F. Snelson Jr., Eds., pp. 163184, Prentice Hall, Englewood Cliffs, NJ, USA, 1989.

[56] K. P. Lampert, C. Schmidt, P. Fischer et al., "Determination of onset of sexual maturation and mating behavior by melanocortin receptor 4 polymorphisms," Current Biology, vol. 20, no. 19, pp. 1729-1734, 2010.

[57] J. Travis, "Size-dependent behavioral variation and its genetic control within and among populations," in Quantitative Genetic Approaches to Animal Behavior, C. R. B. Boake, Ed., pp. 165-187, University of Chicago Press, Chicago, Ill, USA, 1994.

[58] J. C. Trexler, J. Travis, and M. McManus, "Effects of habitat and body size on mortality rates of Poecilia latipinna," Ecology, vol. 73, no. 6, pp. 2224-2236, 1992.

[59] J. C. Trexler, R. C. Tempe, and J. Travis, "Size-selective predation of sailfin mollies by two species of heron," Oikos, vol. 69, no. 2, pp. 250-258, 1994.

[60] J. S. Balsano, E. J. Randle, E. M. Rasch, and P. J. Monaco, "Reproductive behavior and the maintenance of all-female Poecilia," Environmental Biology of Fishes, vol. 12, no. 4, pp. 251-263, 1985.

[61] A. D. Woodhead and N. Armstrong, "Aspects of the mating behaviour of male mollies (Poecilia spp.)," Journal of Fish Biology, vol. 27, no. 5, pp. 593-601, 1985.

[62] J. A. Farr, "Social behavior patterns as determinants of reproductive success in the guppy, Poecilia reticulata Peters (Pisces: Poeciliidae). An experimental study of the effects of intermale competition, female choice, and sexual selection," Behaviour, vol. 74, no. 1-2, pp. 38-91, 1980.

[63] J. Travis and B. D. Woodward, "Social context and courtship flexibility in male sailfin mollies, Poecilia latipinna 
(Pisces: Poecillidae)," Animal Behaviour, vol. 38, no. 6, pp. 1001-1011, 1989.

[64] M. R. Morris, P. F. Nicoletto, and E. Hesselman, "A polymorphism in female preference for a polymorphic male trait in the swordtail fish Xiphophorus cortezi," Animal Behaviour, vol. 65, no. 1, pp. 45-52, 2003.

[65] Y. Iwasa and A. Pomiankowski, "Continual change in mate preferences," Nature, vol. 377, no. 6548, pp. 420-422, 1995.

[66] R. A. Johnstone, "Multiple displays in animal communication:'backup signals' and 'multiple messages'” Philosophical Transactions of the Royal Society B, vol. 351, no. 1337, pp. 329338, 1996.

[67] M. J. Ryan, "Sexual selection, sensory systems, and sensory exploitation," Oxford Surveys in Evolutionary Biology, vol. 7, pp. 157-195, 1990.

[68] G. G. Rosenthal and C. S. Evans, "Female preference for swords in Xiphophorus helleri reflects a bias for large apparent size," Proceedings of the National Academy of Sciences of the United States of America, vol. 95, no. 8, pp. 4431-4436, 1998.

[69] R. Brooks and J. A. Endler, "Female guppies agree to differ: phenotypic and genetic variation in mate-choice behavior and the consequences for sexual selection," Evolution, vol. 55, no. 8, pp. 1644-1655, 2001.

[70] N. M. Kime, A. S. Rand, M. Kapfer, and M. J. Ryan, "Consistency of female choice in the tungara frog: a permissive preference for complex characters," Animal Behaviour, vol. 55, no. 3, pp. 641-649, 1998.

[71] M. J. Ryan and W. E. Wagner Jr., "Asymmetries in mating preferences between species: female swordtails prefer heterospecific males," Science, vol. 236, no. 4801, pp. 595-597, 1987.

[72] M. J. Ryan and A. S. Rand, "Species recognition and sexual selection as a unitary problem in animal communication," Evolution, vol. 47, no. 2, pp. 647-657, 1993.

[73] A. T. Peterson, "Geographic variation in sexual dichromatism in birds," Bulletin of the British Ornitholological Club, vol. 116, pp. 156-172, 1996.

[74] R. Lande, "Models of speciation by sexual selection on polygenic traits," Proceedings of the National Academy of Sciences of the United States of America, vol. 78, no. 6 I, pp. 3721-3725, 1981.

[75] D. E. Rosen, "A vicariance model of Caribbean biogeography," Systematic Zoology, vol. 24, pp. 431-464, 1976. 

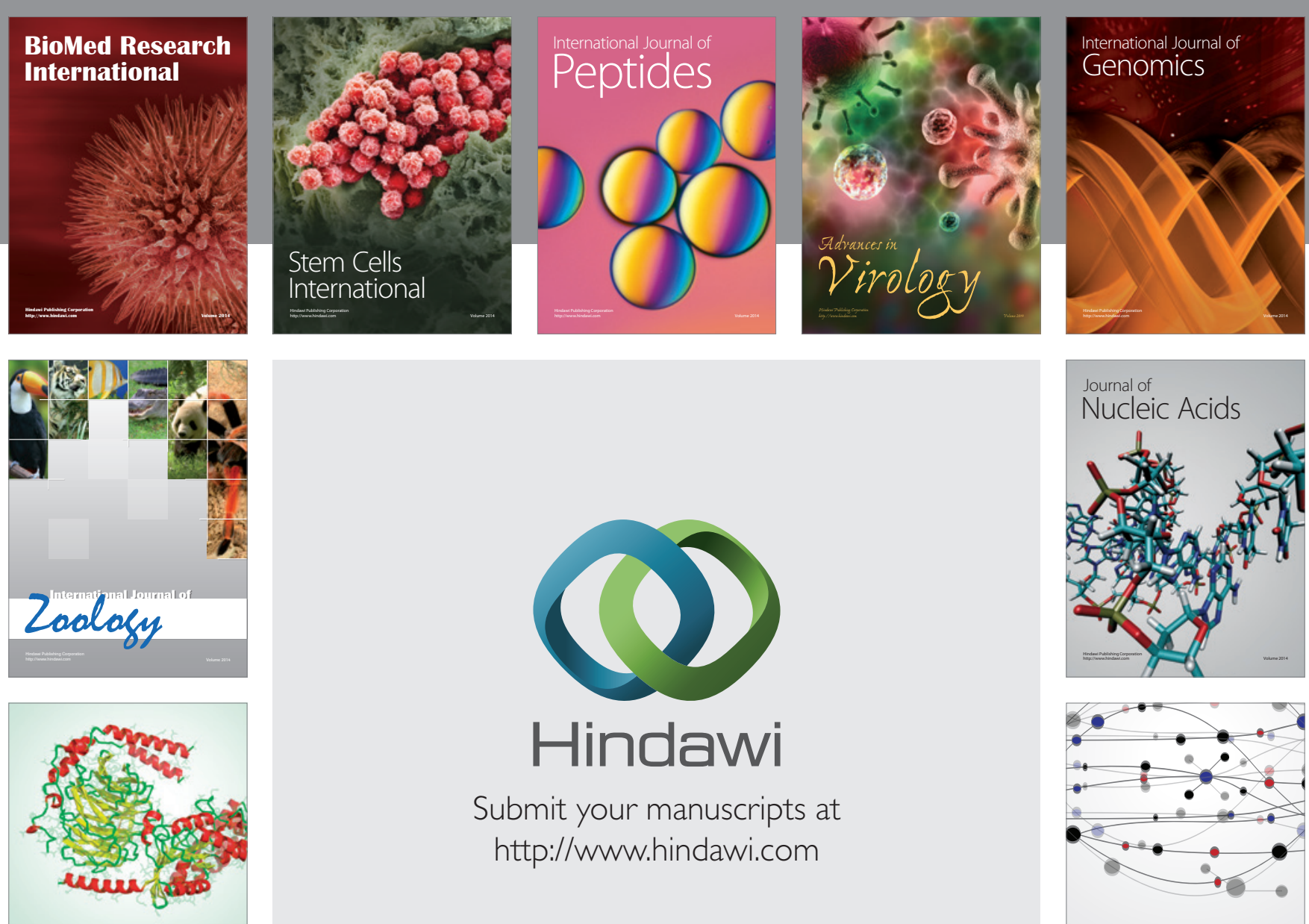

Submit your manuscripts at

http://www.hindawi.com

Signal ${ }^{\text {Jumal }}$ Transduction
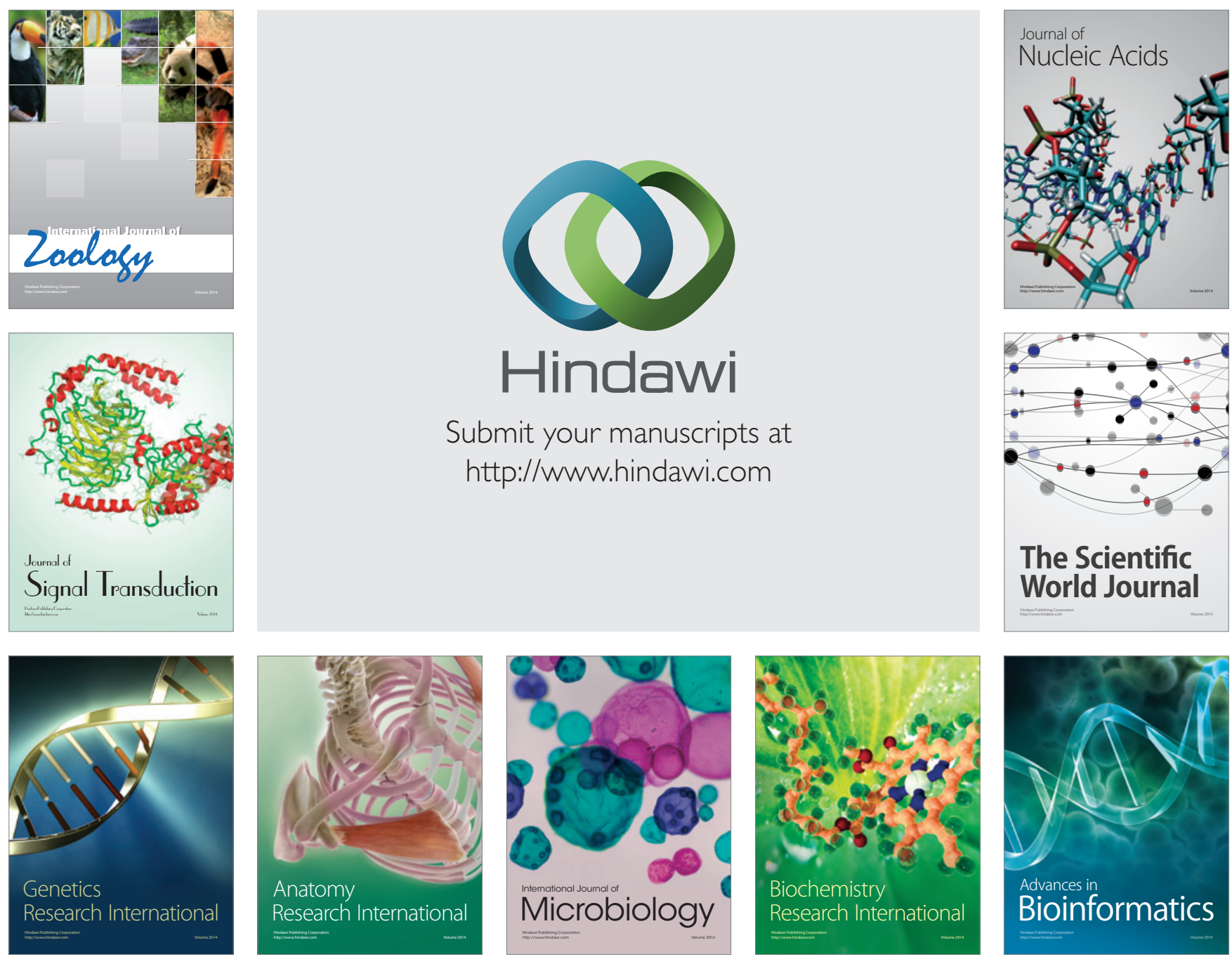

The Scientific World Journal
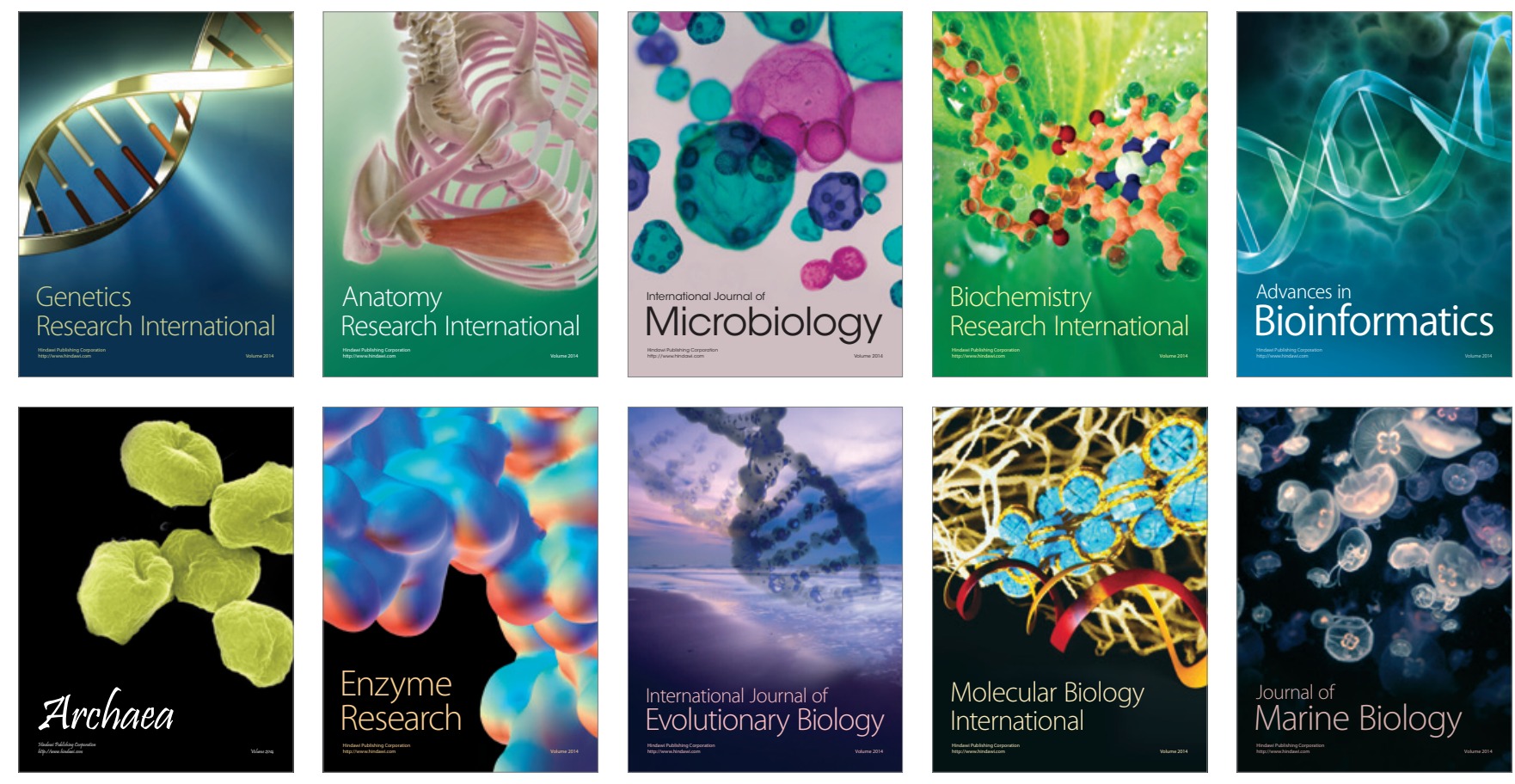